\title{
Editorial
}

\section{Second-Hand Tobacco Smoke and Allergens - Double Jeopardy for Childhood Asthma Exacerbations}

\author{
Zubair Kabir Luke Clancy \\ TobaccoFree Research Institute, Dublin, Ireland
}

Asthma is increasingly being considered a syndrome complex. The mechanistic pathway of asthma is still under exploration. Epidemiological studies, with all their inherent limitations, may provide important insights into causal relationships of a disease. The 2006 US Surgeon General's Report had inferred a causal relationship of asthma and second-hand tobacco smoke (SHS) exposure [1]. There is no safe free level of SHS, which is also classified as a group 1 carcinogen [2]. Four thousand toxic chemicals constitute tobacco smoke.

Steady increases in regional and national smoke-free policies are noted, especially in western societies. But the most vulnerable in society, the children, are silently and involuntarily being exposed to this deadly poison of tobacco smoke. The two most common settings in western society where children are exposed to SHS are in their homes or while travelling by private motor vehicles. The recent UK Royal College of Physicians (RCP) report indicated a 2-fold increased risk of childhood asthma with SHS exposure at home based on meta-analyses of 70 studies [3]. The estimates of childhood asthma vary depending on the type of SHS exposure: in utero or post-natal. Information on acute exacerbations of childhood asthma attributed to SHS (in utero/post-natal) in the presence of childhood exposure to allergens is, however, limited.
In this issue of Respiration, Dong et al. [4] report findings from a large cohort of 8,819 children (mean age $=4.7$ years) sampled randomly from households based in 25 districts of Northeast China. They looked at different forms of respiratory symptoms: from persistent phlegm to current asthma, and from wheeze to doctor-diagnosed asthma both independently and then combined in the presence of childhood allergen and SHS exposure. The findings suggest that current exposure (allergen/SHS) had little or no effect on most of the respiratory symptoms studied. In contrast, in utero and post-natal ( $\leq 2$ years) allergen/SHS exposures were significant risk factors. However, in the presence of allergens, current SHS exposure showed a significant increased risk of doctordiagnosed asthma although such modified effects were greatest when children had either in utero or post-natal SHS exposures.

The present cross-sectional study has both strengths and limitations. Given the complexities of diagnosing childhood asthma and self-reported asthma and asthmalike symptoms, Dong et al. [4] took advantage of a large cohort to report such an association. To the best of our knowledge, no similar studies utilizing such a large cohort of children have yet been reported from any western country. Self-reported data could introduce both misclas-

\section{KARGER}

Fax +4161306 1234

E-Mail karger@karger.ch

www.karger.com
(C) 2010 S. Karger AG, Basel

$0025-7931 / 11 / 0813-0177 \$ 38.00 / 0$

Accessible online at:

www.karger.com/res
Zubair Kabir, MD, PhD

TobaccoFree Research Institute, The Digital Depot

Thomas Street

Dublin 8 (Ireland)

Tel. +353 1511 1226, Fax +3531489 3640, E-Mail zkabir@tri.ie 
sification and recall biases, but given the large sample size, logistic resources in obtaining objective measurements for each individual could be a methodological challenge. The authors have used pet exposure as a proxy measure for allergen exposure, which needs to be validated and reproduced in future studies examining similar research questions.

Despite methodological challenges, the present study findings have both clinical and public health policy implications. Asthma is a persistent condition, still increasing, and impacts the health care system. Maternal smoking rates are very low in Asian countries but 1 in 5 women smoke during pregnancy in the West [5]. Voluntary encouragement of smoke-free home policies is the next logical step forward in most situations. Evidence suggests that $100 \%$ smoke-free homes reduce childhood SHS exposure levels by $20-50 \%$ [6] and comprehensive smokefree policies reduce yearly childhood asthma hospitalization rates by $18 \%$ [7]. Pregnant mothers need special attention as regards tobacco control strategies. Nevertheless, the underlying message of this study [4] is loud and clear - SHS exposure harms children, the most vulnerable, and they should have the right to be protected from it.

\section{Acknowledgement}

Dr. Zubair Kabir has a Career Development Award from the Health Research Board of Ireland.

\section{References}

1 US Department of Health and Human Services: The Health Consequences of Involuntary Exposure to Tobacco Smoke: A Report of the Surgeon General - Executive Summary. US Department of Health and Human Services, Centers for Disease Control and Prevention, Coordinating Center for Health Promotion, National Center for Chronic Disease Prevention and Health Promotion, Office on Smoking and Health, 2006.

2 International Agency for Research on Cancer: Tobacco Smoke and Involuntary Smoking. Lyon, International Agency for Research on Cancer, 2002.
3 Royal College of Physicians (RCP): Passive Smoking and Children. A Report by the Tobacco Advisory Group. London, RCP, 2010.

4 Dong GH, Ren WH, Wang D, Yang $\mathrm{ZH}$, Zhang PF, Zhao YD, He QC: Exposure to secondhand tobacco smoke enhances respiratory symptoms and responses to animals in 8,819 children in kindergarten: results from 25 districts of Northeast China. Respiration 2011;81:179-185.

5 Kabir Z, Clarke V, Conroy R, McNamee E, Daly S, Clancy L: Low birthweight and preterm births 1 year before and after the Irish workplace smoking ban. BJOG 2009;116: 1782-1787.
6 Kabir Z, Alpert HR, Goodman PG, Haw S, Connolly GN, Gupta PC, Clancy L: Effect of smoke-free home and workplace policies on second-hand smoke exposure levels in children: an evidence summary. Pediatr Health 2010;4:391-403.

7 Mackay D, Haw S, Ayres JG, Fischbacher C, Pell JP: Smoke-free legislation and hospitalizations for childhood asthma. N Engl J Med 2010;363:1139-1145. 